\title{
IT Alignment in SMEs: Should it be with Strategy or Process?
}

\author{
Alejandro Cataldo \\ School of Business Systems Engineering - Department of System Engineering \\ Universidad de Talca - Universidad de Atacama \\ Talca, Chile \\ Email: acataldo@utalca.cl
}

\section{Robert McQueen}

Department of Management Systems

University of Waikato

Hamilton, New Zealand

Email: bmcqueen@waikato.ac.nz

\section{Abstract}

For many years researchers have been concerned about the alignment of Information Technology (IT) in businesses. Most of the published research has been focused on understanding the alignment of IT with strategy, but a more recent view is that IT alignment with processes would be better, especially for SMEs. This research presents the two different approaches to measuring IT alignment, then uses the case of a small dental clinic to contribute to understanding these two alternative approaches. The results showed that both strategic alignment and process alignment were important, but strategic guidelines set the framework for the use of IT in the processes. These results contradict the claims of researchers who defend the process approach. This work has implications for practitioners because it again highlights theimportance of IT in a strategic context in SMEs. This research also contributes to the theory of IT alignment in SMEs, and we hope this will encourage other researchers to study which approach is best suited for this type of business.

Keywords: IT alignment, process alignment, strategic alignment, SMEs.

\section{Introduction}

A concern that researchers and practitioners have had for many years has been how companies can effectively align information technology (IT) with business goals (J ohansson and Sudzina 2010). There is strong evidence that a proper IT alignment improves the performance of the company (Chan and Reich 2007), and researchers have sought different ways to tackle the problem of IT alignment in business.

One aspect that some researchers have studied is whether the IT alignment theory is valid for small and medium enterprises (SME) (Chan and Reich 2007). This concern has been raised primarily because the study of IT in business has had a bias towards larger firms (Burgess 2002; Cragg and Tagliavini 2007; Cragg et al. 2007). Some researchers have tried validating existent theory in SMEs, while others have proposed new frameworks exclusively designed for the particular conditions of smaller companies (Blili and Raymond 1993; Levy and Powell 2005). In recent years, some researchers have suggested that in SMEs, IT alignment should be studied with respect to processes, rather than strategy (Cragg and Tagliavini 2007; Tagliavini et al. 2004). These researchers suggest that SMEs often lack a defined strategy against which IT can be aligned and the operational focus of SMEs makes IT likely to be aligned to the processes the company implements (Tagliavini et al. 2004). Recent debate questions whether IT alignment in SMEs should continue to be studied with respect to strategy as has been traditionally been the case, or whether IT alignment should be analysed against processes.

To contribute to this debate, we studied the case of a dental clinic to determine how alignment among IT, strategy and processes was reached. The approach used was qualitative. Two 
researchers collected data through in-depth interviews to key informants and work observation. Both participants and an external researcher validated the data.

This article presents the case and reports the main findings of the study. The remainder of this paper is divided into five sections, which are the literature review, the methodology used, the main results of the study, the results compared to previous literature, and the conclusions and limitations.

\section{Literature Review}

This section summarizes the most relevant published literature related to this study. This section is divided in four subsections, which are research about IT alignment, the traditional approach of IT alignment in SMEs, the new approach of IT alignment based in processes, and the research question which guides the remainder of this study.

\subsection{IT Alignment}

One of the main concerns in the field of technological alignment is to clearly define the meaning of IT alignment. For example, Chan and Reich (2007) quoting Reich and Benbasat defined IT alignment as the degree to which the mission, goals and plans contained in the business strategy is shared and supported by the IT strategy. Henderson and Venkatraman (1999) stated that alignment is the fit and integration between business strategy, IT strategy, business infrastructure and IT infrastructure. Campbell (2005) concluded that alignment is the business and IT working together.

Different definitions have also resulted in different terms to refer to IT alignment. For example, some authors refer to alignment as "fit" (Chan and Reich 2007; Henderson and Venkatraman 1999), while others use the term "connection" (Reich 1993). In turn, other terms used are "integration", "fusion" and "congruence" among others (Chan and Reich 2007). Although they are used almost interchangeably, some cases represent small differences between themself. For example, the term "fit" is associated to a quantitative line of research about alignment and, under this point of view, is linked to mathematical models (Venkatraman 1989a; Venkatraman 1989b). Currently, however, it seems not to be under discussion that the term most dominant is "alignment" (Chan and Reich 2007).

Researchers have also developed models of IT alignment. These alignment models are intended to describe how different elements of an organization interact to achieve an effective alignment. As consequence, they try to represent the IT alignment process from a holistic point of view. The first model of alignment was developed by MIT and is known as MIT90. This model argues that revolutionary changes involving IT investment bring substantial rewards if and only if, the key elements: business strategy, technology, structure, management processes and individuals and roles, remain aligned (Chan and Reich 2007).

Inspired by the MIT90 model, Henderson and Venkatraman (1999) developed the Strategic Alignment Model (SAM), which is perhaps the most widely cited of all models. SAM is based on four key interrelated domains: (1) business strategy, (2) IT strategy, (3) infrastructure and organizational processes and (4) IS processes and infrastructure. Each domain consists of three components. The components of the first two domains comprise scope, distinctive competencies and governance (in the domains of business and IT strategy), and the components of the second two domains consist of: infrastructure, processes and skills (in the domains of administration and IS). According to SAM, alignment is achieved in a bivariate fashion: between business strategy and IT and between organizational infrastructure and information systems (Henderson and Venkatraman 1999).

However, despite its popularity, SAM has some limitations. For example, it is not easy try to use SAM to understand how a company can align its technological resources with their strategic goals (Avison et al. 2004). In fact, several works have been presented to operationalize this model (Avison et al. 2004; Chan and Reich 2007; Coleman and Papp 2006). 
That is one reason why other researchers have sought to expand SAM or propose alternative models. For example, Baets (1992) developed another model by arguing that in many organizations there is no explicit strategy or it is not well known to all members. Kearns and Lederer (2003) developed the factors that influence the alignment, and argued that it was necessary to distinguish between the alignment between business plan/IS plan (BP-ISP) and IS plan/ business plan (ISP-BP). Using the resource-based view, they determined that the main factor to achieve BP-ISP alignment is the role played by the CIO (Chief Information Officer) in the organization.

A significant contribution to the theory of alignment was the development of the strategic orientation of business enterprises (STROBE) and strategic orientation of information system (STROIS) of Venkatraman (1989b) and Chan (Chan et al. 1997a; Chan et al. 1997b), respectively. STROBE was developed to determine the strategic behaviour of an enterprise using six dimensions. Later, using an improved STROBE of eight dimensions, Chan developed STROIS as a complementary tool to evaluate the strategic usage of IT in a company. Together these instruments have been widely used by researchers to quantify the alignment of IT with business strategy (Byrd et al. 2006; Chan and Reich 2007; Hale and Cragg 1996).

\subsection{IT Alignment in SMEs: The Traditional approach based on Strategy}

Since many of the models have been developed for large companies, several researchers have focused on determining validity in the context of small and medium enterprises. For example, Hale and Cragg (1996) adapted and applied the STROBE/ STROIS in New Zealand SMEs. To measure the IT alignment, they used bivariate analysis: matching and moderation. The authors applied the instruments to eight companies to validate them.

On the other hand, Chan et al. (2006) examined the factors affecting IT alignment in a group of business and academic organizations. In their study the authors analysed both large and small organizations. One of their main conclusions was that the organizational size affected alignment IT in business firms but not in academic institutions.

More recently, J ohansson and Sudzina (2010) examined whether alignment is a good or bad influence on company performance. To do this they surveyed a group of 112 Slovak enterprises, both large firms and SMEs. The alignment was measured as a perception of the respondents. The main conclusion was there was a significant difference between high IT alignment and companies with high performance.

Others have developed approaches just for SMEs, such as Blili and Raymond (1993). They argued SMEs have "specificities" that distinguish them from larger firms, so smaller companies need to be studied separately. They developed a framework to align IT with the business proposing a topographic view of the application of IT. Their framework was based on Porter's competitive forces, the value chain and the critical success factors (Blili and Raymond 1993).

Another example of frameworks exclusively designed for SMEs is the work of Levy and Powell (2005). They proposed a new model based on the path of alignment depending on the type of company. Their model classifies SMEs into four types of companies according to the scope of action: (1) efficiency, (2) Co-ordination, (3) Collaboration, and (4) Repositioning. They defined two criteria to classify an SME: the strategic focus and the number of customers. The model helps to align IT using different paths specified by the authors (Levy and Powell 2005; Levy et al. 2001)

\subsection{IT Alignment in SMEs: The New Approach Based on Processes}

Another group of researchers of IT alignment in SMEs have indicated that in this type of organization alignment should be evaluated with respect to processes. Several reasons are put forward to support this position.

The first reason is the small numbers of studies of IT alignment in SMEs compared to those made in large companies. For example, Gutierrez et al. (2006) developed an instrument to measure alignment at the tactical and operational level. They suggested that much of the 
research on alignment was focused only on the strategic dimension, but it was not the only way to align an organization. Based on the SAM model, they constructed a questionnaire that evaluated the degree of maturity at strategic, tactical and operational levels in a SME.

Second, the informality of the roles and inter-functional nature of the tasks suggests that a process-based approach is best suited to the conditions of SMEs. In other words, the scarcity of resources, lack of expertise and focus on the operational questions the traditional view about IT alignment in SMEs (Ravarini et al. 2002; Tagliavini et al. 2004). For example, Tagliavini et al. (2004) say "in particular, a process-based approach seems to properly fit SMEs, where employees carry out inter-functional tasks and do not precisely define their roles". This has led these researchers to develop instruments called "check-up" to assess the alignment of IT with a set of standard processes (Ravarini et al. 2002; Tagliavini et al. 2004).

Thirdly, Cragg et al. (2007) argued that a process approach probably is more important than a strategic one in SMEs, but that approach is less understood and researched. They claimed "This suggests that operational alignment in SMEs could be at least as important as strategic alignment, and possibly of greater importance. Yet operational alignment in SMEs is poorly understood and an under-researched topic". As a consequence, they measured the relationship between IT alignment against processes and IT success. The authors took the framework of PCF (Process Classification Framework) of the APQC (APQC 2008). The APQC is an independent business model that allows industry to identify the activities of a process in a generic enterprise. In their study, they firstly measured the alignment between IT and processes and then evaluated that alignment with IT success.

Finally and most recently, Cragg and Mills (2011), continuing with the study of process-based alignment, assessed how well IT supports business processes in a group of SMEs in New Zealand. Their main conclusion was that "the business process view provides a useful lens for studying IT support. There seems to be much potential for SMEs to improve their IT support for some business processes"

However, recent evidence has emerged to show that the relationship between IT alignment and processes in an SME may still be influenced by the strategy of the company. Cataldo et al. (2012) studying a group of Latin American companies, concluded that both the strategic orientation of SMEs and their processes influenced each other in relation to IT success. Their findings suggest that the relationship between process-level alignment and IT success may be spurious and that strategic alignment may be the confounding variable and that both IT success and process-level alignment could be driven by strategic alignment. As a possible explanation, they speculated that despite the lack of formal and explicit long term planning in SMEs, there always seems to be an implicit strategy that shapes the way that IT is used in processes. Similar explanations have been proposed by other researchers such as Avison et al. (1998) and Levy and Powell (2005).

\subsection{Research Question}

From the foregoing review of previous research, the following research question has been constructed to guide this research:

RQ: What is the driver of the alignment of IT: strategy or processes?

\section{Methodology}

We studied a small dental clinic as a single exploratory study to better understand the scope of the research question, and lay the groundwork for further studies. The study of a SME like a dental clinic has the advantage that this type of business is very autonomous and almost all processes run independently, so they can be analysed as a completely autonomous and quasiisolated unit. Other authors already have researched similar kind of business (Davidson and Heslinga 2006). 
The research strategy used was case studies. For data collection we used semi-structured interviews and work observation. Both the strategy and techniques of data collection and analysis are part of what is known as qualitative research methods (Bryman and Bell 2007).

The decision to use qualitative research methods depends on the questions raised. Qualitative research can be effective for questions such as "What is happening?" and "How is it happening?" (Bluhm et al. 2010; Lee et al. 1999; Lee 1999). Qualitative research is unique in its ability to conduct problems of description, explanation and interpretation of a phenomenon. It is also essential to discover deeper processes in individuals, teams and organizations, as well as understand how these processes occur in time. Additionally, qualitative research is critical to gain an understanding of the experience of individuals and how they interpret (Bluhm et al. 2010).

For reliability and validity of the study we followed the recommendations made by Creswell (2009) and (Yin 2009). The respondents were the owner of the clinic and his receptionistadministrator because both are key users of the systems. Each interview lasted between two and three hours. All sessions were videotaped and digital audio recorded. Also, interviewers took field notes.

We used an interview protocol to ensure reliability. Collected data were also triangulated with data collected through observation of work and documents. As an important part of the interviews were based on how the key informants executed their activities, some parts of the interviews were later transcribed and almost all data were analysed directly using qualitative data analysis software. The authors acknowledge a methodological limitation on this procedure.

To ensure the validity of the findings, two people conducted the interviews: a principal researcher and an assistant. After each interview, interviewers asked for feedback from participants. Additionally, a person outside the group of researchers who had access to interviews also validated the analysis.

\section{Results}

This section is divided into two subsections. The first subsection briefly describes the case. The second subsection presents the analysis performed. To maintain confidentiality of identities, the names used are fictitious.

\subsection{Brief Description of the Case}

OceanDental is a dental clinic in Chile which employs five staff. The clinic was founded 2010 by a dentist specializing in endodontic services, who we will call Patrick. Patrick has nearly 20 years of experience as a dentist, worked 19 years in a family dental clinic and also had an Internet company that was forced to close after the dotcom crisis. Despite its failure, this experience provided him with two fundamental lessons: firstly, he acknowledges that while he had his company, he learned everything he knows about strategic management, and secondly, during that period he became convinced that IT could give him a competitive advantage over his competitors. After he paid all the debts of his Internet business, Patrick opened OceanDental that only treats endodontic patients. Currently, the clinic has a good reputation and attracts patients from the entire country. A feature of the business is that other dentists or large clinics send their patients to be treated.

A key role is played by the administrative assistant and receptionist, who we will call Soledad. She is a dental assistant with 15 years of experience. She has been in that position since the opening of the clinic but she had also previously worked with Patrick. Soledad is a skilled IT worker who learned computing while working at an international electronics company where she worked six years. As assistant and receptionist, she is responsible to book and confirm the appointments' patients, receive their payments, and make daily reports to Patrick about income. In addition, shemust do banking and administrative tasks and when a patient finishes 
the treatment, she has to print and deliver the report to the patient and send it via e-mail to her dentist.

According to Patrick, one of the characteristics of the clinic is that it makes extensive use of dental and information technologies. In fact, the company has two major systems: DentalVision, which is a dental management system (DMS) used to store all the information of the clinic, and ClinicSystem which is software to store the radiographs. ClinicSystem is integrated with the digital dental x-ray equipment used in the clinic. The integration between the data generated by equipment and the software is achieved through ad-hoc applications developed by Patrick and freelance programmers hired by him.

\subsection{Results}

Almost all of OceanDental's internal processes are computerized, and the clinic uses only paper documents for its external transactions, aiming for a paperless environment. Like any small dental clinic, OceanDental's processes are highly centralized in the receptionist (see Figure 1). Their information is stored on an external server, but Soledad and Patrick have access. Only the daily income accountability process is manual. Although DentalVision generates income reports, Soledad prepares a daily report that is delivered to Patrick.

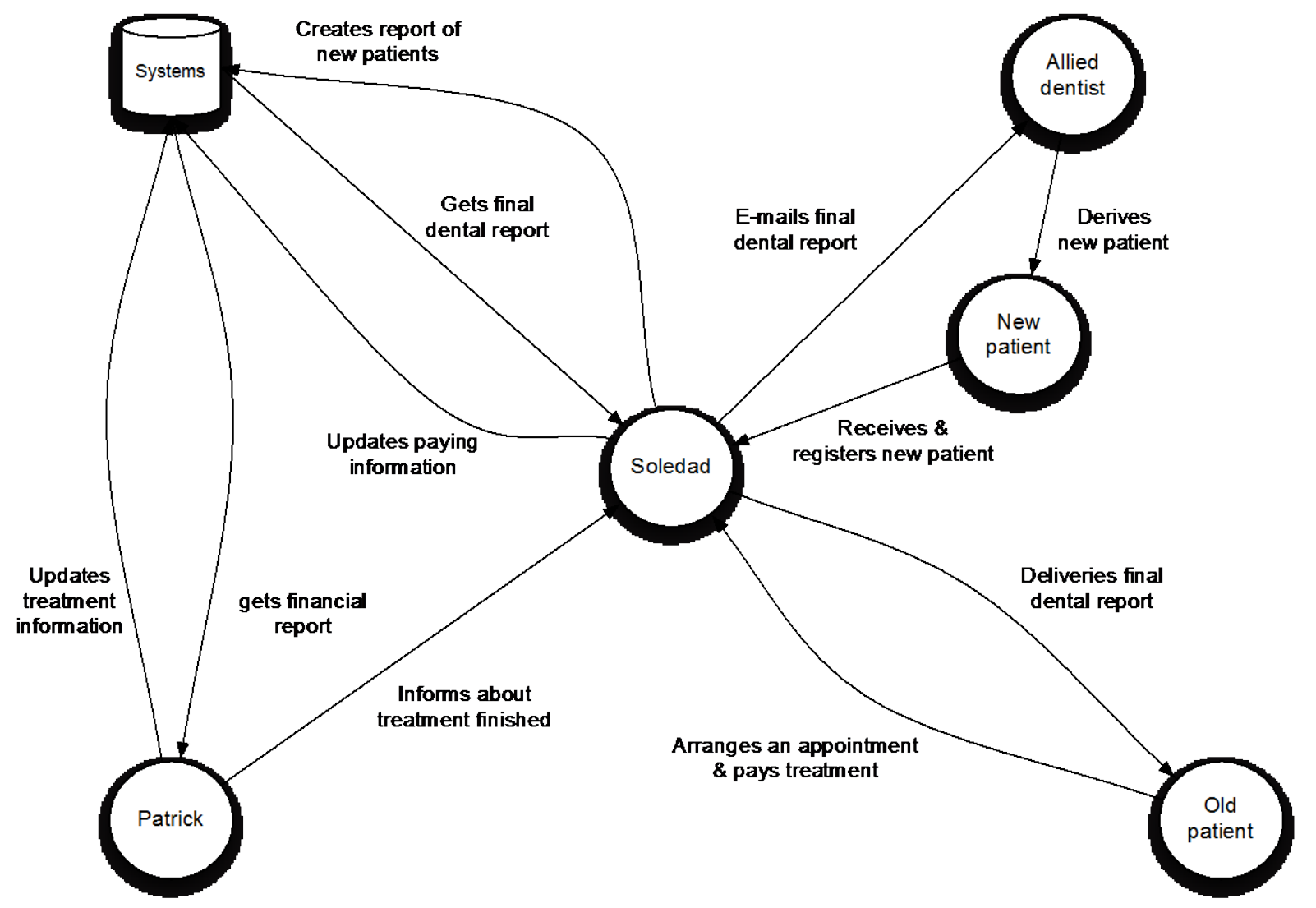

Figure 1: Diagram of main information flow in OceanDental: Processes are highly centralized in Soledad.

\subsection{Aligning IT with Business Processes}

According to Lockamy and Smith (1997), a process is a sequence of pre-defined activities executed to achieve a pre-specified type or range of results. Consequently, IT aligned with processes should effectively and efficiently support this sequence of activities.

It was found that IT was strongly aligned with the processes of the clinic. To illustrate this, we describe a part of the patient care process, specifically the sub-process to take x-rays and deliver reports of treatment. First, the X-rays are taken using digital equipment. This equipment is connected directly to the dentist's computer and he inserts the X-ray in a 
customized form. This form is filled using a Word macro developed by Patrick and freelance programmers who he hired. This form is saved in PDF format on the file server of the clinic and the ClinicSystem. When the patient finishes his treatment, Soledad accesses the report of treatment on her computer, prints it out and delivers it to the patient in a folder. In addition, she also e-mails the report to the doctor who referred the patient.

Several additional examples of IT alignment with processes were found. For example, the use of macros for creating forms has reduced the processing time of reports of patients from thirty minutes to just four minutes. Another example is the process of admission of new patients. Soledad told us how they entered each new patient: "patient arrives with her X-ray then I scan it so that the doctor can see it on his computer. If I don't do that, the doctor will not be able to work, then ... I mean, he can still work but he won't have something important which is the X-ray"

\subsection{Strategic Alignment}

There are several definitions of what is strategy, some of them complementary. For example, for Porter (2001), strategy is the creation of a unique and valuable position, involving a different set of activities. In that sense, he describes a good strategy as having (a) to consider a long timeframe (10+ years), (b) to define one or more types of positions (based on variety, needs or access) and (c) to establish the trade-off between alternative directions, and what not to do.

Hax (2010) reported that the classic definition of strategy, "to achievesustainable competitive advantage" is dangerous. For him a good strategy has to be focused on the customer rather than on competition as in Porter's definition. So, for Hax the strategy should create the conditions so that a company (a) achieves long-term sustainable financial returns, (b) creates activities not imitable, (c) avoids commoditizing their products or services, and (d) looks at the customer so as to be able to attract her, satisfy her and retain her.

For Hax (2010), the most sustainable strategy is onein which the company succeeds in creating the strongest bond with the customer. In that sense, this is achieved when the lock-in is obtained with the client, i.e., switching costs for the customer are so high that she decides to stay with the company. When a company creates a lock-in, its competitors are in a state of lockout, and the whole system begins to work for the company.

Although OceanDental did not have a written strategy, during the interview with Patrick we could identify many of the features that, according to Hax and Porter, must be part of a strategy. Table 1 presents evidence about OceanDental's strategic characteristics identified during the interview with Patrick.

Alignment between IT and strategy requires that IT supports one or more of the strategic features identified in table 1. We were able to confirm that several of these strategic features were supported by IT (column 3 of table 1). For example, reports that are delivered to patients and their dentist are key for Patrick, and therefore the format of the reports and their presentation must distinguish them from the traditional reports that are made by " $98 \%$ of endodontists" who deliver an "X-ray in an small envelope". Table 1 shows that IT plays a key role in the report provided to patients. According to Patrick "this is a barrier to entry" for other specialists who would want to do the same.

\subsection{Strategic IT Alignment with processes: the chicken or the egg?}

OceanDental is clearly a company whose IT is aligned with both the strategy and the processes. However, the question remains what was the driver of the alignment of IT: strategy or processes?

For OceanDental the strategic decisions taken by Patrick were a key driver in the incorporation and use of IT. For example, he said "That's what I offer: a specialty clinic with the latest technology". Clearly in this case the use of technologies (not just information but also dental 
treatment technologies) was a strategic choice taken by Patrick, that is, he made that decision before identifying which technologies he would utilize or how it would be done.

For Patrick the use of technology brought several advantages: (1) improved the customer experience, giving them greater confidence about the quality of service, (2) created a barrier to entry for other dentists (he believes his colleagues still do not use IT as intensively as he does), and (3) increased profitability per patient because he is able to charge a higher price than the market average for treatment. This was confirmed by Soledad when she said "I think the price is fair.. he has all the technology needed".

However, the response of what technologies to use or how to do it depended on the processes and their design. For example, Patrick made the decision to create Word macros to automate and to do more efficient process to prepare patient reports. Another example is the decision of Patrick to create a paperless clinic acquiring ClinicSystem and DentalVision. This decision was related to design internal processes fully digitized in a paperless environment. Soledad said "now everything is digital... I don't have papers. There aren't folders with paper, or anything of those things ... all is digital."

In summary, although OceanDental did not design a formal strategy, the company showed a high level of strategic direction, which was an orientation where IT played a key role. In turn, these guidelines acted as a platform on which the processes that the company would implement were subsequently designed. Meanwhile, specific commercial systems and technologies were selected to support these processes. In sum, for Patrick alignment between his strategy and IT occured prior to the alignment between processes and IT.

\section{Discussion}

Researchers have reported that most SMEs do not have formal planning processes (Cragg et al. 2007; Hale and Cragg 1996; Levy and Powell 2005). However, Table 1 shows significant evidence that the company has a strategic direction that has guided many of the decisions made by Patrick as owner of the clinic. Cases like OceanDental that have no formal strategy but execute a strategy have been reported in literature (Chan and Reich 2007; Levy and Powell 2005; Venkatraman 1989b).

On the other hand, our results show that there was an alignment between OceanDental strategic and processes levels. Both types of IT alignment are consistent with a large body of published research. For example, Chan and Reich (2007) discuss the strategic alignment of IT, while Cragg and Mills (2011) present evidence on the alignment of IT with processes in SMEs.

Our results indicate that both strategic and process alignment of IT occurred in OceanDental, and that strategy alignment occurred before the process alignment. This is consistent with findings of other researchers. Chan and Reich (2007) claimed "clearly defined business goals and vision are often first steps in an alignment process." The results are also consistent with Cataldo et al. (2012) indicating a correlation between strategic alignment and processes. Also, the relationship between strategy, processes and infrastructure manifested in OceanDental is consistent with the SAM model, which establishes that alignment is a tripartite relationship between three domains (Coleman and Papp 2006; Henderson and Venkatraman 1999). 


\begin{tabular}{|c|c|c|}
\hline Strategic feature & Patrick's comment & IT strategic alignment \\
\hline $\begin{array}{l}\text { Positions based } \\
\text { on variety }\end{array}$ & $\begin{array}{l}\text { This kind of clinic doesn't exist } \\
\text { [anywhere else] in Santiago. It's } \\
\text { just endodontic. }\end{array}$ & Not identified. \\
\hline Trade off & $\begin{array}{l}\text { If someone asks me 'can you make } \\
\text { a dental filling?' I answer no, you } \\
\text { have to go to your dentist. If they } \\
\text { ask 'will you do a filling?' I say no, I } \\
\text { don't care to do that. }\end{array}$ & Not identified. \\
\hline $\begin{array}{l}\text { Long-term } \\
\text { returns }\end{array}$ & $\begin{array}{l}\text { It is attractive because I'm earning } \\
\text { more, spending more, [but] the } \\
\text { delta is the same as it was } 10 \\
\text { months ago [when I started], but at } \\
40 \% \text { capacity. [If I] grow only } 10 \% \\
\text { more...these amounts will become } \\
\text { quite attractive. }\end{array}$ & $\begin{array}{l}\text { The visible and intensive use of } \\
\text { technology creates in the patient a } \\
\text { feeling of confidence that makes } \\
\text { them willing to pay more money } \\
\text { and not complain about that. }\end{array}$ \\
\hline Non-imitation & $\begin{array}{l}\text { I can offer more [technology] than } \\
\text { my competition. I can offer } \\
\text { discounts because we are a group. }\end{array}$ & $\begin{array}{l}\text { Use of Word macros to automate } \\
\text { reporting and reduce form filling } \\
\text { time from } 30 \text { to } 4 \text { minutes. }\end{array}$ \\
\hline $\begin{array}{l}\text { Non- } \\
\text { commoditization }\end{array}$ & $\begin{array}{l}\text { The reports are very important } \\
\text { because [the patient] pays } 400 \text { or } \\
600 \text { dollars for a scan and they take } \\
\text { their report and say 'Hey look super } \\
\text { expensive but this is my scan!' For } \\
\text { the traditional } 98 \% \text { of } \\
\text { endodontists, all the patient gets is } \\
\text { an x-ray in an small envelope. }\end{array}$ & $\begin{array}{l}\text { Delivery of digital information to } \\
\text { patients and referring dentists. }\end{array}$ \\
\hline Look-in & $\begin{array}{l}\text { I used to have only a chair. Fully } \\
\text { saturated! ... No chance to react. } \\
\text { And the reference doctor called me } \\
\text { and I said him I can't treat the } \\
\text { patient, sorry'. An endodontist who } \\
\text { can't receive a patient is wrong, } \\
\text { because the endodontist attends } \\
\text { urgencies! }\end{array}$ & $\begin{array}{l}\text { Use of website to build confidence } \\
\text { in a patient with information about } \\
\text { treatments, CV and clinic's facilities }\end{array}$ \\
\hline $\begin{array}{l}\text { Strategic } \\
\text { alliances }\end{array}$ & $\begin{array}{l}\text { I have a pool of [referring] dentists } \\
\ldots \text { who aren't endodontists, and } \\
\text { when they need to do a endodontcy, } \\
\text {... everyone sends me five, six, ten } \\
\text { or fifteen patients per month }\end{array}$ & $\begin{array}{l}\text { Using e-mail to send digital reports } \\
\text { to the patient's dentist }\end{array}$ \\
\hline
\end{tabular}

Table 1. Strategic features identified in OceanDental and its alignment with IT.

However, the results contradict the findings of some researchers that process alignment is more important than strategic alignment in SMEs (Cragg and Tagliavini 2007; Cragg et al. 2007; Tagliavini et al. 2004). Our results show both type of alignment were concurrent in OceanDental. Perhaps, it can be speculated that process alignment might be more relevant in companies where there is not a formal strategy or strategic guidance from top management. However, in SMEs where there is a clear strategic orientation (even if not made explicit), the role of strategic alignment may still be just as important as the alignment at the process level. 


\section{Conclusions}

There is a broad consensus that IT alignment can produce significant improvements in business. However, in the context of SMEs, this consensus seems to have shades of agreement. While some researchers apply the theory of alignment to both large and small companies, other researchers argue that strategic IT alignment theory does not fit with the conditions of SMEs, and therefore they advocate a process-based analysis rather than a strategic one.

Our study analysed the case of a small dental clinic with the aim of trying to explore the issue and contribute to the debate on IT alignment in SMEs. Our results showed that in the case studied, both strategic alignment and process alignment appeared concurrently and seemed to be interrelated. In the case of the dental clinic, there was a strong alignment of IT with the strategy driven primarily by the strong visionary role that the owner has based on the intention to use the latest technologies, both dental and IT, in his business. As a result, IT strongly supports this vision of the owner of the company so that both strategy and processes have reached a high level of integration with IT.

The alignment of IT with both strategy and processes has been reported in previous studies. As consequence, these results are also consistent with other studies that validate the theory of traditional alignment in SMEs. However, these results do seem to contradict some recent findings that measurement of IT alignment in SMEs is better based on process than on strategy. In this regard, these findings extend the results of Cataldo et al. (2012) who found a correlation between the alignment of IT with both strategy and processes.

The authors acknowledge two important limitations of this study. Firstly, because this research was based on a single case, its external validity is limited, although it follows the recommendations of previous studies about case studies. Secondly, the case study's business, geographical and cultural environments are very specialized, leaving open the question of whether the results would be replicable in other conditions.

Despite the above, this work may have implications for both practitioners and researchers. For practitioners, this study again highlights the importance that IT has when it is organized in a strategic context in accordance with the processes of the company. For researchers, the study provides new information on the theory of IT alignment in SMEs and the debate that has been built whether it is best analysed against strategy or processes. We think and hope that this work may encourage other researchers to try to provide additional insight on this problem in different contexts and environments.

\section{References}

APQC. 2008. "Process Classification Framework," APQC, Houston, USA.

Avison, D., J ones, J., Powell, P., and Wilson, D. 2004. "Using and Validating the Strategic Alignment Model," Strategic Information Systems (13), pp. 223-246.

Avison, D.E., Eardley, W.A., and Powell, P. 1998. "Suggestions for Capturing Corporate Vision in Strategic Information Systems," Omega (26:4), pp. 443-459.

Baets, W. 1992. "Aligning Information Systems with Business Strategy," J ournal of Strategic Information Systems (1:4), pp. 205-213.

Blili, S., and Raymond, L. 1993. "Information Technology: Threats and Opportunities for Small and Medium-Sized Enterprises," International J ournal of Information Management (13:6), pp. 439-448.

Bluhm, D.J., Harman, W., Lee, T.W., and Mitchell, T.R. 2010. "Qualitative Research in Management: A Decade of Progress," J ournal of Management Studies).

Bryman, A., and Bell, E. 2007. Business Research Methods, (Second ed.). Oxford University Press, USA. 
Burgess, S. 2002. "Managing Information Technology in Small Business: Challenges and Solutions. Introduction," in Managing Information Technology in Small Business: Challenges and Solutions, S. Burgess (ed.). Hershey, PA: IGI Global.

Byrd, A., Lewis, B.R., and Bryan, R.W. 2006. "The Leveraging Influence of Strategic Alignment on It Investment: An Empirical Examination," Information \& Management (43:3), pp. 308-321.

Campbell, B. 2005. "Alignment: Resolving Ambiguity within Bounded Choices," PACIS 2005, Bangkok, Thailand, pp. 54.

Cataldo, A., McQueen, R., and Hardings, J . 2012. "Comparing Strategic It Alignment Versus Process It Alignment in Smes," J ournal of Research and Practice in Information Technology (44:1), pp. 43 - 57.

Chan, Y., Huff, S., Barclay, D., and Copeland, D. 1997a. "Business Strategic Orientation, Information Systems Strategic Orientation, and Strategic Alignment," Information Systems Research (8:2), pp. 125-150.

Chan, Y., Huff, S., and Copeland, D. 1997b. "Assessing Realized Information Systems Strategy," J ournal of Strategic Information Systems (6:4), pp. 273-298.

Chan, Y., Sabherwal, R., and Thatcher, J . 2006. "Antecedents and Outcomes of Strategic Is Alignment: An Empirical Investigation," IEEE Transactions on Engineering Management (51), pp. 27-47.

Chan, Y.E., and Reich, B. 2007. "It Alignment: What Have We Learned?," J ournal of Information Technology (22:4), pp. 297-315.

Coleman, P., and Papp, R. 2006. "Strategic Alignment: Analysis of Perspectives," Proceedings of the 2006 Southern Association for Information Systems Conference, J acksonville, Florida, pp. 242-250.

Cragg, P., and Mills, A. 2011. "It Support for Business Processes in Smes," Business Process Management J ournal (17:5), pp. 697-710.

Cragg, P., and Tagliavini, M. 2007. "Evaluating Information Systems Alignment in Small Firms." University of Southern Queensland, Toowoomba, Australia, pp. 38-48.

Cragg, P., Tagliavini, M., and Mills, A. 2007. "Evaluating the Alignment of It with Business Processes in Smes," 18th Australasian Conference on Information Systems (ACIS 2007), Toowoomba: University of Southern Queensland, pp. 38-48.

Creswell, J.W. 2009. Research Design: Qualitative, Quantitative, and Mixed Methods Approaches, (Third ed.). Los Angeles: Sage Publications, Inc.

Davidson, D.E., and Heslinga, D.D. 2006. "Bridging the It Adoption Gap for Small Physician Practices: An Action Research Study on Electronic Health Records," Information Systems Management (24:1), pp. 15-28.

Gutierrez, A., Orozco, J., and Serrano, A. 2006. "Using Tactical and Operational Factors to Assess Strategic Alignment: An Sme Study," in: European and Mediterranean Conference on Information Systems (EMCIS). Costa Blanca, Alicante, Spain.

Hale, A.J ., and Cragg, P.B. 1996. "Measuring Strategic Alignment in Small Firms," Information Systems Conference of New Zealand (ISCNZ'96), Palmerston North, NewZealand: IEEE Computer Society Washington, DC, USA.

Hax, A. 2010. The Delta Model: Reinventing Your Business Strategy. Cambridge: Springer Verlag.

Henderson, J .C., and Venkatraman, N. 1999. "Strategic Alignment: Leveraging Information Technology for Transforming Organizations," IBM Systems J ournal (38:2-3), pp. 472484. 
J ohansson, B., and Sudzina, F. 2010. "Can Both Good and Bad Alignment of Business and Information Strategies Lead to High Business Performance?," 14th IBIMA Conference, K. Soliman (ed.), Istanbul, Turkey, pp. 1382 - 1387.

Kearns, G.S., and Lederer, A.L. 2003. "A Resource-Based View of Strategic It Alignment: How Knowledge Sharing Creates Competitive Advantage," Decision Sciences (34:1), pp. 1-29.

Lee, T., Mitchell, T., and Sablynski, C. 1999. "Qualitative Research in Organizational and Vocational Psychology, 1979 - 1999," J ournal of Vocational Behavior (55:2), pp. 161-187.

Lee, T.W. 1999. Using Qualitative Methods in Organizational Research. California: Sage Publications, Inc.

Levy, M., and Powell, P. 2005. Strategies for Growth in Smes: The Role of Information and Information Systems. United Kingdom: Butterworth-Heinemann.

Levy, M., Powell, P., and Yetton, P. 2001. "Smes: Aligning Is and the Strategic Context," J ournal of Information Technology (16:3), pp. 133-144.

Lockamy, A., and Smith, W.I. 1997. "A Strategic Alignment Approach for Effective Business Process Reengineering: Linking Strategy, Processes and Customers for Competitive Advantage," International J ournal of Production Economics (50:2-3), pp. 141-153.

Porter, M. 2001. "Strategy and the Internet," Harvard Business Review (79:3), pp. 62-79.

Ravarini, A., Tagliavini, M., Buonanno, G., and Sciuto, D. 2002. "Information System Checkup as a Leverage for Sme Development," in Managing Information Technology in Small Business: Challenges and Solutions, S. Burgess (ed.). Hershey PA: Idea Group Inc (IGI), pp. 63-82.

Reich, B.H. 1993. "Investigating the Linkage between Business and Information Technology Objectives: A Multiple Case Study in the Insurance Industry."

Tagliavini, M., Faverio, P., Ravarini, A., and Sciuto, D. 2004. "Monitoring the Strategic Effectiveness of Sme Information System," 49th ICSB World Conference, J ohannesburg: University of Pretoria, South Africa.

Venkatraman, N. 1989a. "The Concept of Fit in Strategy Research: Toward Verbal and Statistical Correspondence," Academy of Management Review (14:3), pp. 423-444.

Venkatraman, N. 1989b. "Strategic Orientation of Business Enterprises: The Construct, Dimensionality, and Measurement," Management Science (35:8), pp. 942-962.

Yin, R.K. 2009. Case Study Research: Design and Methods, (Fourth ed.). USA: Sage Publications, Inc.

An earlier version of this paper was presented at the Australasian Conference on Information Systems (ACIS) 2014 in Auckland, New Zealand.

Copyright: (C) 2015 Cataldo \&McQueen. This is an open-access article distributed under the terms of the Creative Commons Attribution-NonCommercial 3.0 Australia License, which permits non-commercial use, distribution, and reproduction in any medium, provided the original author and AJ IS are credited. 


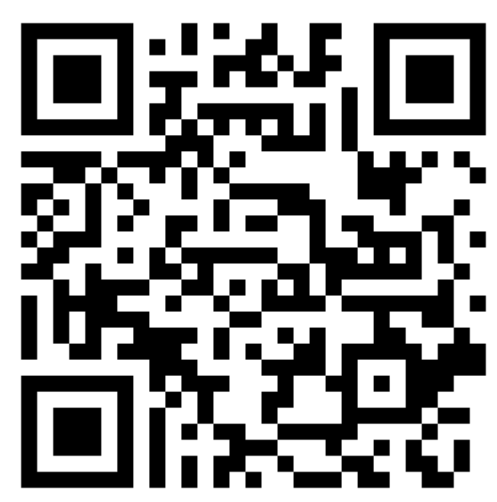

